\title{
Preference Reversal in Risky Choices under Time Pressure
}

Najam Saqib, Ryerson University, Canada

Eugene Chan, University of Toronto, Canada

\section{EXTENDED ABSTRACT}

One pervasive aspect of decision-making under time pressure is the salience of negative information. Research has repeatedly concluded that "the harassed decision maker" tends to weigh the possible negative consequences of his or her action heavily to the relative disregard of the possible positive rewards of those same actions. In this paper, we propose that the salience of negative information under time pressure not merely leads to risk-aversion, but that it may reverse an individual's usual preferences.

Individuals are typically either risk-seeking or risk-averse. Research outside the time pressure domain has shown that, when negative information becomes salient, risk-seeking individuals perceive little room for further gains but large likelihood of accruing losses, causing them to adopt risk-averse behaviours. In a choice between a modest-but-certain and greater-but-uncertain gamble, risk-seeking individuals tend to adopt risk-averse behaviours whereas risk-averse individuals tend to adopt risk-seeking ones. Meanwhile, for risk-averse individuals, the salience of negative information only adds to the extant negativity, causing them to adopt riskseeking behaviours with the hopes of removing the negative state. We extend these findings to the time pressure domain and suspect that time pressure would likewise be one instance where individuals would reverse their usual risk preferences to adapt to the salience of negative information. We examine this possibility in three studies.

In Study 1, participants with positive (negative) affect chose a riskier (certain) lottery to a NHL hockey game when there was no time pressure, but adopted the certain (riskier) approach under time pressure. We thus demonstrated the basic outline of our hypothesis.

In Study 2, we used a gambling task in which participants stated their willingness to gamble for specific dollar amounts. We also added a thought protocol to assess the participants' emphases on positive versus negative outcomes during the gambling process. Under no time pressure, risk-seeking (risk-averse) individuals focused more on positive (negative) outcomes than negative (positive) ones. Under time pressure, however, risk-seeking (risk-averse) individuals focused more on negative (positive) outcomes than positive (negative) ones. The focus on positive versus negative information for risk-seeking and risk-averse individuals reversed under time pressure. These differences in foci on positive versus negative outcomes mediated the preference reversal.

In Study 3, we explored a similar preference reversal in regulatory orientation using a consumer choice task involving toothpaste and grape juice brands as well as investment choices. Under no time pressure, promotion- (prevention-) focused individuals preferred promotion- (prevention-) framed and risk-seeking (risk-averse) brands and choices. Under time pressure, however, promotion- (prevention-) focused individuals preferred prevention- (promotion-) framed and risk-averse (risk-seeking) brands and choices.

Taken together, the three studies suggest that individuals tend to reverse their preference for risky choices under time pressure compared to situations under no such constraint. It is important to note, however, that preference reversals in risky choices do not occur because risk-seeking individuals want to avoid risks or that risk-averse individuals want to take risks, but that they need to. Risk-seeking individuals adopt risk-averse behaviours when negative information becomes salient because such an approach can secure gains, in line with the goals of risk-seeking. Conversely, risk-averse individuals adopt risk-seeking behaviours when negative information becomes salient because such an approach can avoid further losses, in line with the goals of risk-aversion. Thus, preference reversals are not in innate risk preferences, but in the perception and adoption of the behaviours that best serve their objectives given the circumstance. Our findings have important marketing implications since consumers often face decision-making tasks under time pressure in everyday life.

\section{REFERENCES}

Arkes, Hal R., Lisa T. Herren, and Alice M. Isen (1988), “The Role of Potential Loss in the Influence of Affect on RiskTaking Behavior," Organizational Behavior and Human Decision Processes, 42 (October), 181-93.

Baron, Reuben M. and David A. Kenny (1986), "The ModeratorMediator Variable Distinction in Social Psychological Research: Conceptual, Strategic, and Statistical Considerations," Journal of Personality and Social Psychology, 51 (December), 1173-82.

Ben Zur, Hasida and Shlomo J. Breznitz (1981), "The Effect of Time Pressure on Risky Choice Behavior," Acta Psychologica, 47 (February), 89-104.

Crowe, Ellen and E. Tory Higgins (1997), "Regulatory Focus and Strategic Inclinations: Promotion and Prevention in Decision-Making," Organizational Behavior and Human Decision Processes, 69 (February), 117-32.

Higgins, E. Tory (1997), "Beyond Pleasure and Pain," American Psychologist, 52 (December), 1280-1300.

(1998), "Promotion and Prevention: Regulatory Focus as a Motivational Principle," in Advances in Experimental Social Psychology, Vol. 30, ed. Leonard Berkowitz and Mark P. Zanna, New York: Academic Press, 1-46.

Isen, Alice M. and Nehemia Geva (1987), "The Influence of Positive Affect on Acceptable Levels of Risk: The Person with a Large Canoe Has a Large Worry," Organizational Behavior and Human Decision Processes, 39 (April), 14554.

Johnson, Eric J. and Amos Tversky (1983), “Affect, Generalization, and the Perception of Risk," Journal of Personality and Social Psychology, 45 (July) 20-31.

Kahneman, Daniel and Amos Tversky (1979), "Prospect Theory: An Analysis of Decision Under Risk," Econometrica, 47 (March), 263-91.

Lee, Angela Y. and Jennifer L. Aaker (2004), "Bringing the Frame into Focus: The Influence of Regulatory Fit on Processing Fluency and Persuasion," Journal of Personality and Social Psychology, 86 (February) 205-18.

Lerner, Jennifer S., Deborah A. Small, and George Loewenstein (2004), "Heart Strings and Purse Strings: Carryover Effects of Emotions on Economic Decisions," Psychological Science, 15 (May), 337-41.

Lockwood, Penelope, Christian H. Jordan, and Ziva Kunda (2002), "Motivation by Positive or Negative Role Models: Regulatory Focus Determines Who Will Best Inspire Us," Journal of Personality and Social Psychology, 83 (October), 854-64. 
Novemsky, Nathan and Daniel Kahneman (2005), “The Boundaries of Loss Aversion," Journal of Marketing Research, 42 (May), 119-28.

Nowlis, Stephen M. (1996), "The Effect of Time Pressure on the Choice between Brands that Differ in Quality, Price, and Product Features," Marketing Letters, 6 (October), 287-95.

Payne, John W., James R. Bettman, and Eric J. Johnson (1988), "Adaptive Strategy Selection in Decision Making," Journal of Experimental Psychology: Learning, Memory, and Cognition, 14 (July), 534-552.

Pham, Michel T. (1998), "Representativeness, Relevance, and the Use of Feelings in Decision Making," Journal of Consumer Research, 25 (September), 144-59.

Pham, Michel T. and E. Tory Higgins (2005), "Promotion and Prevention in Consumer Decision Making: The State of the Art and Theoretical Predictions," in Inside Consumption: Consumer Motives, Goals and Desires, ed. S. Ratneshwar and David G. Mick, London: Routledge, 8-43.

Prelec, Drazen and George Loewenstein (1991), "Decision Making Over Time and Under Uncertainty: A Common Approach," Management Science, 37 (July), 770-86.

Scholer, Abigail A. and E. Tory Higgins (2008), "Distinguishing Levels of Approach and Avoidance: An Exploration Using Regulatory Focus Theory," in Handbook of Approach and Avoidance Motivation, ed. Andrew J. Eliot, Hillsdale, NJ: Erlbaum, 489-504.

Scholer, Abigail A., Steven J. Stroessner, and E. Tory Higgins (2008), "Responding to Negativity: How a Risky Tactic Can Serve a Vigilant Strategy," Journal of Experimental Social Psychology, 44 (May), 767-74.

Schwarz, Norbert and Gerald L. Clore (1983), "Mood, Misattribution, and Judgments of Well-Being: Informative and Direct Functions of Affective States," Journal of Personality and Social Psychology, 45 (September), 513-23.

Sitkin, Sim B. and Amy L. Pablo (1992), "Reconceptualizing the Determinants of Risk Behavior," The Academy of Management Review, 17 (January), 9-38.

Svenson, Ola and Anne Edland (1987), "Change of Preferences under Time Pressure: Choices and Judgments," Scandinavian Journal of Psychology, 28 (4), 322-330.

Tversky, Amos and Daniel Kahneman (1981), "The Framing of Decisions and the Psychology of Choice," Science, 211 (January), 453-8.

Watson, David, Lee A. Clark, and Auke Tellegen (1988), "Development and Validation of Brief Measures of Positive and Negative Affect: The PANAS Scales," Journal of Personality and Social Psychology, 54 (June), 1063-70.

Wright, Peter (1974), "The Harassed Decision Maker: Time Pressures, Distractions, and the Use of Evidence," Journal of Applied Psychology, 59 (October), 555-61.

Zhou, Rongrong and Michel T. Pham (2004), "Promotion and Prevention across Mental Accounts: When Financial Products Dictate Consumers' Investment Goals," Journal of Consumer Research, 31 (December), 125-35. 